\title{
CORPUS-BASED RESEARCH ON VARIATION \\ IN ENGLISH LEGAL DISCOURSE
}

Teresa Fanego and Paula Rodríguez-Puente, eds.

Amsterdam/Philadelphia: John Benjamins, 2019

\section{VIRGINIA MATTIOLI}

Independent Researcher

virginiamattioli@gmail.com

Corpus-based Research on Variation in English Legal Discourse is a collection of chapters that aim to examine and summarise the great range of research on legal discourse undertaken over the past 30 years. As explained in the introduction (Chapter 1), the main interest of the editors, Teresa Fanego and Paula RodríguezPuente, is the synergy of forensic linguistics with register analysis, register variation and historical pragmatics. The introduction offers an in-depth exploration of forensic linguistics, highlighting its main aims and its strict relationship to corpus-based methods, followed by an overview of the most renowned contributions to register analysis and variation (Biber 1988; Bhatia 1993; Šarčević 1997), as well as of the main features of historical pragmatics. Finally, the introduction provides an overview of the volume and the chapters included in it. The book comprises two sections: the first is dedicated to the synchronic approximation of legal language, sub-divided into chapters on crosslinguistic and cross-genre studies, and the second focuses on diachronic studies. The editors explain that this organisation permits the representation of each of the four trajectories into which, according to Łucja Biel, corpus-based research on legal language can be classified: external, internal, temporal, and crosslinguistic variation (2010: 10).

Due to its prominence in the area, Corpus-based Research on Variation in English Legal Discourse has already been reviewed by several scholars (Feng 2019; Xin and 


\section{Reviews}

Wang 2019; Han 2020; Williams 2020), each of whom is as concerned as the editors with classifying the collected contributions. Feng (2019) divides the chapters into three groups according to the data-analysis techniques adopted by the editors: descriptive, predictive and prescriptive. Xin and Wang (2019) follow the four trajectories proposed by Biel (2010), whereas Williams (2020) and Han (2020) maintain the division into synchronic and diachronic studies by describing the 11 chapters according to their order of appearance in the book. Considering the great variety that characterizes the volume, whose contributions in some cases offer interesting results in both synchronic and diachronic terms, the present review will follow yet another order. According to the disciplinary perspective from which the collected contributions approach legal language variation, the 11 chapters will be divided into five groups representing linguistic, pragmatic, rhetorical, functional and social perspectives.

Chapters 2, 4, and 7 start from the linguistic prism to analyse the specific features or general tendencies of a particular legal subgenre. Giuliana Diani (Chapter 2) performs a cross-linguistic analysis of land contracts. After studying the distinctive textual and linguistic features of these contracts in American English and Italian texts, the author concludes that the legal register presents a similar macrostructure in both languages but with different punctuation and linguistic resources. Land contracts share similarities in both languages with regard to the scarce use of pronouns, the abundance of long and complex sentences, hypotactic structures, and anaphors, but they differ in their expressions of modality: American English texts show a preference for deontic modals (expressing obligation, prohibition and permission) that result in a greater use of collocations and formulaic expressions, whereas Italian texts display a tendency for the "normative indicative" (Sarčević 1997: 138-140) -i.e. simple present indicative with a clear prescriptive function, as in "Il venditore [...] si impegna a cedere la stessa libera da oneri iscrizioni ipotecarie "The seller [...] agrees to assign the same free of charge mortgage registrations" (43, emphasis added) - and "deonticallycharged nominals" — such as diritto 'right', obbligo 'duty', or carico 'responsibility' (44) - and hence greater variation. Ruth Breeze (Chapter 4) aims to identify similarities and differences across four legal genres, contrasting their parts of speech patterns with the British National Corpus (BNC). Specifically, the selected documents represent four different genres from the broad area of commercial law: legal academic writing in the form of research or opinion articles; judgments and opinions from courts of higher instance in the UK and USA; documents from business law, including different types of contracts and agreements; and legislation relating to commercial law, in the form of the Companies Act 2006 (UK) and the Model Business Corporation Act 2005 (USA). The results reveal two main trends: on the one hand, academic articles, 


\section{Reviews}

judgments and opinions are characterised by complex sentences and, on the other hand, legal documents and laws are marked by passive constructions and elliptical relative clauses. In Chapter 7, Douglas Biber and Bethany Grey diachronically compare law reports with non-legal registers (fiction, newspaper articles and science research articles) in terms of their use of colloquial linguistic features (popularisation) and phrasal complexity (economy). In particular, the authors focus on the similarity of the register of law reports with that of academic writing, due to the formal and dense style shared by both registers. However, while academic writing has changed dramatically over time, law reports have undergone a perceptible but very limited diachronic change resulting from an increase in phrasal complexity features, such as phrasal modifiers, and in the use of some features related to traditional literate discourse, like relative clauses, noun complement clauses and nominalizations.

From a more pragmatic perspective, Chapters 6 and 8 focus on subjectivity and interpersonality. As Stanisław Goźdź-Roszkowski states in Chapter 6, "[a]ccording to a stereotypical and somewhat idealized perception of legal discourse, there should be no need for stance expressions" (123), as the register should be completely objective without any kind of emotive or opinion expressions. To provide a contrast to this general idea, Goźdź-Roszkowski explores the relationships between stance, discipline, and genre, regarding 'noun-that' constructions (e.g. 'the fact that') as a productive resource to express evaluation and comparing the use of these constructions in academic journals and judicial opinions. In most cases, the constructions examined include epistemic nouns used to express certainty (e.g. 'assertion', 'conclusion', or 'knowledge', mostly in academic journals) and likelihood (e.g. 'argument', 'idea', 'impression', or 'possibility', mostly in judicial opinions), demonstrating the importance of expressing stance in legal texts. In chapter 8, Paula RodríguezPuente describes the evolution of law reports between the $16^{\text {th }}$ and $20^{\text {th }}$ centuries in contrast to developments in other legal subgenres (i.e. parliamentary acts, proclamations, and statutes) in the same period. Specifically, Rodríguez-Puente discusses the presence and function of nominative, accusative, genitive and reflexive pronouns across the examined subgenres. Again, the study demonstrates the existence of authors' presence in law reports, hybrid texts that present both subjective and objective linguistic features.

Using a rhetorical approach, Nicholas Groom and Jack Grieve (Chapter 9) examine the types and sequences of rhetorical moves in a set of patent specifications over 150 years (1711-1860) to corroborate the three conditions underlying the evolutionary theory of genre change: variation, reproduction, and selection. The fulfilment of all three conditions offers the authors the chance to reflect on the 


\section{Reviews}

paradoxical character of textual genres, which represent normative stable conventions (i.e. the reproductive aspect) but which are, at the same time, affected by continuous diachronic changes (i.e. variation and selection).

Chapters 3 and 5 examine courtroom discourse from a functional perspective. Cristina Lastres-López (Chapter 3) focuses on the function of 'if-conditionals', comparing courtroom and parliamentary discourse in English, French and Spanish. Following a cognitive-functional approach based on Halliday and Matthiessen's (2004) metafunctions, the author shows that in all the analysed languages and contexts, conditionality is mainly used with an ideational normative function to explain the conditions under which an action is performed. In Chapter 5, Randi Reppen and Meishan Chen depart from a previous study conducted by Culpeper and Kytö (2010) to explore the variation over time (Modern versus Contemporary English), across subregisters (dividing each courtroom discourse into four sections, representing the different stages of the trial and their respective functions), and across diatopic varieties (British versus American English) of three-word lexical bundles in spoken courtroom language, such as 'in this case', 'at that point', or 'evidence will show'. The several similarities identified across time and subregisters demonstrate the complementary nature of the different stages of the trial, each with its own functions but sharing a common purpose.

Finally, Chapters 10 and 11 consider the social representation that arises from legal texts. Anu Lehto (Chapter 10) examines the evolution of the representation of citizens and the monarchy in British Acts of Parliament from the $19^{\text {th }}$ to the $20^{\text {th }}$ century, analysing the semantic preferences and prosodies of the collocates of each social group. The results show that in the passage from a more traditional monarchy to the modern nation-state, citizens' social and political prominence (and collocates) augments and their depiction, which was initially focused on crimes and punishments, changed gradually towards an increasing interest in their rights and wellbeing. From the same perspective, Claudia Claridge (Chapter 11) analyses the evolution of the representation of drunkenness in courtroom discourse from the $17^{\text {th }}$ to the $20^{\text {th }}$ century. Drunkenness seems to have been used as a negotiation tactic within courtrooms, used by defendants to reduce citizens' legal responsibility and by judges as a cause for blame. Moreover, the diachronic interpretation of the results further emphasises the relationship between legal discourse and socio-political transformations, showing how references to drunkenness changed across the four centuries analysed according to changing social attitudes to alcohol consumption: from its $17^{\text {th }}$-century acceptance as a common activity in any social group to its moral condemnation during the Victorian era. The variations examined in Chapters 10 and 11 indicate the necessary correlation between legal language and society, underlined by the 


\section{Reviews}

change in the former in relation to the social roles of the participants and the socio-political tendencies of any given period.

The emphasis on the practical implications of legal language in the real world and on the strict relationship between language and law (Schane 2006) is another main strength of the volume, which clearly displays the mutual influence of linguistic, political and social aspects within legal discourse. Such a correlation between language and either specific or general human phenomena is demonstrated in each chapter of the book. Thus, for example, Chapter 5 shows how the different stages and goals of a trial are reflected in courtroom language; Chapter 6 demonstrates how language is affected by the necessary subjectivity of human nature, which leaves its trace even in legal texts that are supposedly objective and free of opinions; Chapter 7 describes the effect of the progressive democratisation of legal processes and institutions on the increase in colloquial linguistic features in law reports; and Chapters 10 and 11 explicitly demonstrate the influence of social perceptions on the linguistic representation of social groups.

In conclusion, one of the most valuable features of the volume is indeed its great variety. Corpus-based Research on Variation in English Legal Discourse offers multiple visions of the current state of legal corpus linguistics research on variation in the English language, presenting some of the various methods, topics, subgenres and perspectives from which it can be approached as well as some of its main social and political implications. On the one hand, such ample variety, which represents the expansiveness of the legal language field, makes the volume a valuable reference for students, scholars and professionals of both Linguistics and Law, who can find in its pages valuable contributions to the main aspects of the English legal register and its variation. The volume also provides some inspiration for further studies and useful data about a wide range of methodological resources for their realisation, including analytical techniques and specialised corpora and tools. On the other hand, the variety of aspects dealt with in the volume is also the source of its main limitation: it attempts to cover an area of study which is perhaps too wide to be presented in a single book and offers only a superficial overview of the discipline, prioritising the variety of the themes over their in-depth analysis. Similarly, such great variety hinders the organization of the volume, making it difficult to follow a rigorous classification, as demonstrated by the chapters which could have been included in any of the sections (e.g. Chapter 5). In fact, even if the case studies share a common methodological corpus-based approach, each one focuses on specific registers or subgenres, analysing different features and adopting diverse perspectives rather than contributing to the exhaustive examination of a specific aspect of the variation affecting legal discourse. 


\section{Reviews}

\section{Works Cited}

Bhatı, Vijay K. 1993. Analysing Genre: Language Use in Professional Settings. Harlow: Pearson Education.

BIBER, Douglas. 1988. Variation Across Speech and Writing. Cambridge: Cambridge U.P.

BIEL, Łucja. 2010. “Corpus-Based Studies of Legal Language for Translation Purposes: Methodological and Practical Potential". In Heine, Carmen and Jan Engberg (eds.) Reconceptualizing LSP: Online Proceedings of the XVII European LSP Symposium 2009. Aarhus: Aarhus School of Business, Aarhus University: 1-15.

Culpeper, Jonathan and Merja Kytö. 2010. Early Modern English Dialogues: Spoken Interaction as Writing. Cambridge: Cambridge
Feng, Haoda. 2019. "Teresa Fanego and Paula Rodríguez-Puente (eds.): Corpus-Based Research on Variation in English Legal Discourse". Applied Linguistics 2019: 1-4.

HallidaY, Michael A.K. and Christian M.I.M. MATtHiEssen. 2004. An Introduction to
Functional Grammar. $3^{\text {rd }}$ edition. London: Edward Arnold.

HAN, Zhengrui. 2020. “Book Review: Teresa Fanego and Paula Rodríguez-Puente (eds), Corpus-Based Research on Variation in English Legal Discourse". Discourse Studies 22 (2): 243-245.

ŠARČEvić, Susan. 1997. New Approach to Legal Translation. The Hague: Kluwer Law International.

SCHANE, Sanford. 2006. Language and the Law. London: Bloomsbury.

Williams, Christopher. 2020. "Review of Fanego, Teresa and Paula Rodríguez-Puente eds. 2019. Corpus-based Research on Variation in English Legal Discourse". Research in Corpus Linguistics 8 (1): 178-194.

XIN, Zhiying and Jiawei WANG. 2019. "Corpusbased Research on Variation in English Legal Discourse, Teresa Fanego and Paula Rodríguez-Puente, eds (2019)". The International Journal of Speech, Language and the Law 26 (1): 127-132. 